\title{
Meta-discourses of disability among people with Multiple Sclerosis
}

\author{
Ana-Maria Jerca ${ }^{1}$ \\ York University, Toronto, Canada
}

\begin{abstract}
This study qualitatively analyzes meta-discourses surrounding the term disabled by people with Multiple Sclerosis (MS) on the Reddit sub-community r/MultipleSclerosis. It explores medical and social factors influencing whether people with MS identify as disabled, resist the term, or identify in other ways, and discusses how people with MS are reclaiming the discourse of disability. MS, an auto-immune disease targeting the central nervous system, is unique in that it can be "invisible": it does not always affect the person who has it in noticeable ways. Consequently, the progression of the illness is only one factor cited when users discuss how they identify with the term disabled-social and logistical factors have an influence as well. Therefore, I suggest that instead of prescribing a term to refer to people with disabilities, it may be better to accept the many ways in which individuals with disabilities refer to themselves.
\end{abstract}

Keywords: discourse analysis; disability; online forums

\section{Introduction}

At times, political correctness doctrines can gloss over individual attitudes towards which terms are appropriate, accurate ways to refer to people belonging to certain groups-particularly socially disadvantaged ones - and which are not. ${ }^{2}$ The discourse of disability is no exception. There is no unanimously agreed-upon and politically correct way to refer to somebody with a disability. The terms with which to do so are still changing. Labels that are now considered archaic and derogative like crippled and handicapped have undergone what Cameron calls a "discursive shift" (2012, p. 128). That is, these terms have "drift[ed] away from [their] earliest senses" (Cameron, 2012, p. 128) and become taboo.

At the time Cameron was writing, the preferred term to describe someone with a disability was disabled (2012). But, since labels attempting to be politically correct must keep changing because imposing politically correct speech on people is ineffectual (Cameron, 2012) without corresponding institutional support and reform (see, for example, Ehrlich \& King, 1994), just like crippled and handicapped, disabled — what used to be considered the "correct" term - has acquired some negative connotations, as I will explain later. Consequently, new terms for the same idea are being proposed, such as person with a disability, differently abled, and others. While these terms

\footnotetext{
${ }^{1}$ Corresponding author: ajerca@yorku.ca

2 "Political correctness" is certainly a loaded term. While it can be used with negative connotations to refer to socalled "impositions" on one's freedom of speech, I am using it in this paper to refer to interventions in language use, particularly those by governments and other social institutions, which are focused on replacing terms deemed "insulting and objectionable" to various groups with more widely acceptable terms (Cameron, 2012, p. 117).
} 
may vary in their acceptability by the disabled community, it is important to note that none of them are neutral. As disability scholar Williams writes, "there is [...] no neutral language with which to begin the process of discussing chronic illness and disability" (1996, p. 194). What terms like person with a disability and differently abled are, however, is more or less reflective of the model of disability that they emerge from, i.e., social, medical, or affirmative.

\subsection{Models of disability}

According to Barnes and Mercer, the social model of disability "puts the onus on society to accommodate people with physical impairments, emphasizing that social factors as much as biological ones are the source of disabled people's social disadvantages" (1997, p. 3). These social disadvantages are comparable in degree to what other discriminated or oppressed groups face. Disability scholar Jan Grue writes that "disability is inevitably compared to other social categories that have connoted [...] marginality, oppression, and resistance" (2016, p. 99). Grue explains that in the Anglo-American discourse of disability, disablement is seen as a form of oppression, resulting from "active or passive discrimination and the abrogation of rights, or alternatively from the insufficient interpretation of rights as they apply to people with impairments" (2016, p. 76).

Stamou et al. (2016) show what subscribing to the social model of disability translates to verbally. In a study of the discursive construction of disability on Facebook groups for people with disabilities, they found that groups and individuals who subscribed to the social model of disability tended to describe themselves and other disabled people using labels like people with: physical disability, mobility problems/difficulties, wheelchairs, special needs (Stamou et al., 2016). What is notable about these labels is that they are "person-first" (Bolt, 2003, p. 519). That is, the term person precedes the mention of disability, which presumably aims to emphasize that people with disabilities are still individuals and should not be defined by their impairments.

The social model of disability contrasts with the medical model, which stresses the view of disability as a deficit (Stamou et al., 2016). Unlike the social model, this kind of discourse can have the disabling effect of casting people with disabilities as victims (Oliver, 1996) and portraying disability as an individual's "personal tragedy" rather than a form of social oppression (Barnes and Mercer, 1997, pp. 3-4). Unsurprisingly, in their study, Stamou et al. (2016) found that people who subscribed to this model of disability used labels that clearly emphasized lack of ability, like visually impaired people for people who are blind, effectively identifying people who are blind by their disability. They also found labels like people with hearing loss for the Deaf. ${ }^{3}$ Though this might seem contradictory to the medical model by being person-first language, it is worth noting that, under the social model, Deaf people were referred to as the deaf community (Stamou et al., 2016), which, by focusing more on the collective than on their impairment, seems much more in line with the social model's values.

Under the affirmative model, the last model that Stamou et al. (2016) discuss, stress is placed on the experiences of people with disabilities and these individuals are considered "in terms of their abilities rather than their limitations" (pp. 3-4, my emphasis). Users who subscribed to this model reconstructed their disabilities as abilities in what the authors see as an attempt "to manage

\footnotetext{
${ }^{3}$ The capitalization of the ' $d$ ' in Deaf is intentional. Just like the term "deaf community", capitalizing the 'd' helps distinguish community membership from the mere medical fact of hearing loss. It is also important to recognize that sign languages (American or otherwise), which are distinct from English and other spoken languages, contribute towards the formation of a distinct Deaf community among its users. This is an aspect that does not exist for other disabilities.
} 


\section{META-DISCOURSES OF DISABILITY AMONG PEOPLE WITH MS}

a negative identity" (Stamou et al., 2016, pp. 8-9). Consider the example below of a post by a Deaf user subscribing to this model:

It still is a bit fun sometimes. You can't hear annoying sounds from outside and at night to keep you awake, during 4th of July you don't get a headache, you can always turn off your hearing aids so you don't have to listen to things you don't want to hear, and a bunch of other stuff. And with certain aids you can switch between hearing or not. So it's kind of fun a bit to be deaf and I'm proud of who I am (Stamou et al., 2016, pp. 8-9).

Evidently, the author of this post views their disability as a positive aspect of their identity, one that enables them to do something that able-bodied people cannot: consistently choose what they hear. For similar reasons, some labels used to describe being disabled under this model were: people with exceptional/unique/special abilities, wonderful creatures, and exceptional people (Stamou et al., 2016). However, while refreshingly positive because they do not focus on impairments, these terms have the disadvantage of being extremely vague. For one, they don't only single out people with disabilities - someone without a disability could also be called an exceptional person. Additionally, they do not provide any information about what accommodations should be made for a disabled individual, at least not in the same way that impairment-focused terms do. Furthermore, in the affirmative model, the discourse of disability was complicated by the fact that Stamou et al. (2016) also found that users still used labels such as disabled people and people with special needs, which were reminiscent of the medical model.

\subsection{Which $\operatorname{term}(\mathrm{s})$ to use?}

We can see then that not only is there overlap in ways to refer to people with disabilities across the models, but also that within each model, there are terms that are disputed. For instance, "person-first" language is considered to be overly defensive by the National Federation of the Blind (NFB) because it "portrays blind people as touchy and belligerent" (Bolt, 2003, p. 519). More generally, the NFB considers it as what Stamou et al. would call an "overlexicalization" (2016, p. 10), arguing that "a blind person needs to be called a person who is blind no more than, say, an intelligent person needs to be referred to as a person who is intelligent" (Bolt, 2003, $\mathrm{p}$. 519). Likewise, the term (person with) special needs is disputed by the disability scholar Tom Shakespeare, whose thoughts are reminiscent of Grue's claims about disability also stemming from social oppression. Shakespeare writes:

Disabled people need the same things as everyone else: they need housing, education, employment, information, and services. In fact, disabled people have ordinary needs, which are not normally met. The result is that they have to rely on particular kinds of helping services which are seen as rendering them abnormal and inferior. The problem lies not in the individual, but in the services and environments which render the disabled person excluded and needy (2000, p. 9).

So, it seems there is no middle ground in terms of the terminology used to refer to people with disabilities. Labels in the affirmative model can be too vague, labels focusing on the social factors that contribute to disability can have the effect of "lumping together" people with disabilities, and labels "focusing too much on the impairments [...] deflect attention from the systematic way in which the environment excludes people from participation in civil society" (Williams, 1996, p. 195). 


\subsection{The study}

What remains to be investigated, however, are the meta-discourses - or the discourses about discourse - around terms referring to disability. Naturally, people who have disabilities are aware of at least some of the many labels that exist to refer to them, but, as Stamou et al (2016) show, it is important to consider how people with disabilities refer to themselves. Of course, the answer to this question will vary from person to person and depend on the disability/disabilities one may have. However, for the purposes of this paper, I have chosen to focus on disabling symptoms caused by a specific illness, Multiple Sclerosis (MS), and how individuals who have MS prefer to be referred to in terms of the various labels associated with disability. What is particularly unique about MS is that it is "an intermittent and fluctuating health condition" that "flares up" and is often invisible (Shakespeare, 2018, p. 58-59). In other words, the disabling effects of MS can be temporary, so while in remission (which I will explain in the next section), it can be difficult to see that an individual has MS, which may then affect how they identify in terms of the term disabled.

Given the many discourses of disability, the goal of this study was first to identify and explain the variety of ways in which individuals with MS identify with the word disabled, that is, whether they use it, resist it, or use another term to describe themselves. To answer this question, I conducted a discourse analysis of posts on the sub-community r/MultipleSclerosis of the social media platform, Reddit. I explain my methodology and results in Sections 3 and 4, respectively. However, the second - and perhaps, more important - goal of this paper was to explore how labels relating to disability and the choices to identify with or resist them are rooted in social and medical contexts, which often intertwine and can even contradict each other. So, considering these goals, I do not attempt to propose an "appropriate" or "politically correct term" for referring to people with disabilities. Instead, I argue that the discourse of disability in terms of MS is highly individualized and that perhaps this should be the case for other disabilities as well.

\section{What is MS?}

Having given some background information about the discourses of disability and introduced my research questions, I will now explain MS in further detail. According to the MS Society of Canada's website (2018), MS is "an auto-immune disease of the central nervous system". The disease targets and attacks the myelin — a protective tissue that covers the nervesand causes inflammations in the brain. The myelin, which is responsible for transmitting nerve impulses through nerve fibres, may get damaged because of these inflammations, which can result in the disruption of communication between the nerve cells such that "the body does not receive the instructions necessary to perform basic functions like speaking, seeing, walking, and learning" (MS Society of Canada, 2018). The symptoms of MS are "extreme fatigue, lack of coordination, weakness, tingling, impaired sensation, vision problems, bladder problems, cognitive impairment, and mood changes" (MS Society of Canada, 2018), but it is important to note that not everybody who has MS experiences these symptoms to the same degree, or even at all.

It is also important to mention that MS comes in different forms. There are at least four different types of MS, and which type an individual is diagnosed with affects what kinds of symptoms they experience. This in turn may affect the degree to which they identify with the word disabled. The first type of MS is called Clinically Isolated Syndrome (CIS). This refers to "a single episode of neurological symptoms"-i.e., the ones I outlined above-"suggestive of multiple sclerosis" (MS Society of Canada, 2018). The second type of MS is Relapse-Remitting MS (RRMS), which "is characterized by unpredictable but clearly defined relapses (also known as 


\section{META-DISCOURSES OF DISABILITY AMONG PEOPLE WITH MS}

flare-ups) during which new symptoms appear or existing ones get worse" (MS Society of Canada, 2018). Once the relapsing symptoms are over and the individual is back to "pre-relapse function", they are considered to be in remission. As I've already mentioned, it can be difficult to identify that a person has MS while they are in remission because they are not currently experiencing any of the disabling symptoms of the disease. Consequently, during remission (and perhaps otherwise), people with RRMS may not consider themselves disabled. The third type of MS is an advanced stage of RRMS called Secondary Progressive MS. It is characterized by worsening symptoms of MS and fewer remissions. Finally, the fourth type of MS is known as Primary Progressive MS (PPMS). In this case, there is "a slow accumulation of disability, without defined relapses [or] periods of remission" (MS Society of Canada, 2018), meaning that the degree to which a person with PPMS is disabled by it increases with time, which can also impact a person's choice to identify as disabled.

\section{Methodology}

Now that I've explained the different types and symptoms — or lack, thereof — of MS, I will discuss the methodological approach I took to complete this study. As I mentioned above, my data come from the subreddit r/MultipleSclerosis. I exclusively searched for and analyzed texts written by people who have MS that meta-discursively discussed about how they relate to the word disabled.

I went about gathering the data in two ways: first, I made a post outlining the objective of my paper and asking users how they identify in terms of the word disabled. ${ }^{4}$ A total of 19 people responded to my post, some in detail and others elaborating when I asked for more information. In total, this method yielded 23 responses. In addition, I used an automatic script to collect the text of 1,000 Reddit posts over a period of 5 months (March-July 2018). The posts were then searched by means of a regular expression in order to pinpoint all uses of the keywords disability, disabled, person with a disability, and disabling. In total, 252 posts - including the responses to my post and my own comments - were found to contain at least one of these keywords. After isolating the posts that meta-discursively talked about disability - that is, after discounting the posts in which disability was solely used to refer to salary compensation or where somebody other than the author was being called disabled, as well as my own comments, etc.- - I was left with 32 posts varying from 50-200 words in length. These posts were analyzed in terms of how each respondent identified with the word disabled: whether they used it, resisted it, or used another label to describe themselves.

Before delving into the results, I must mention that this study is qualitative rather than quantitative. Therefore, though not an immense number in itself, these 32 responses still provided interesting insights into the discourse of disability in relation to MS.

\section{Results}

\subsection{Why and how some people with MS choose to identify as disabled}

One of the most surprising results of this research was that, when users did relate to the word disabled, there was very little focus on what the "correct" way to do so was, i.e., as person with a disability, disabled person, disabled, differently abled, or another label. Only one user overtly explained their choice of identifying as a person with a disability in response to my question. They wrote:

\footnotetext{
${ }^{4}$ I provide my original post in the appendix.
} 
(1) Person with a disability. In college I worked with all Deaf people and they taught me "human first" language. A person uses a wheelchair they aren't "wheelchair bound" its just a tool. ${ }^{5}$

This unique finding is reminiscent of Cameron's (2012) point that imposing some type of language on speakers - be it politically correct language in general or something more specific like "person-first" language to refer to disabilities - is not very effective. While this user specifically writes that they were taught person-first constructions, it is certain that, in a subreddit like r/MultipleSclerosis and elsewhere, other users with disabilities have seen this same construction and have heard the rationale for it, and yet they still used the term disabled. So, rather than sharing their relationships with the different ways of identifying as disabled, most users focused on why they use that label in the first place.

Authors who used the word disabled to describe themselves often showed a lack of agency in being disabled, which was reminiscent of the medical model of disability described earlier. Consider the examples below:

(2) people don't understand that I can't handle lifting things above like $15 \mathrm{lbs} .$. the pain is nuts. considering living a normal life, that is not in the cards for the foreseeable future. so, yea. I suffer from MS and it disables me. everyone's dealt a different hand with this.

(3) I am disabled with chronic fatigue. I sleep any where from 12 to $14 \mathrm{hrs}$ a day and ya there are times it pisses me off, but I don't let it dominate me life because [...] I would be constantly unhappy

In (2) and (3), MS and chronic fatigue, respectively, are portrayed as responsible for the authors' disabilities. In other words, the illness and its symptoms are the ones doing the disabling and causing suffering, which implies that the authors are not responsible for their inability to live "normally". The author in (2) uses the metaphor of playing cards and not knowing what kind of hand one will be dealt to emphasize how MS affects every individual in a different, unpredictable way, further resisting being held responsible for not living "a normal life".

Along the same lines, one user explicitly established a dichotomy between being disabled and being personally responsible for one's physical or cognitive limitations as seen in (4). For the author of (4), identifying as disabled is not only a way to come to terms with their illness and its symptoms, but also a way to resist labels that undermine the effects of the illness and imply personal responsibility for them, like lazy. While laziness is something one can control, this user does not have any choice in being fatigued, and this lack of agency is one of the reasons they choose to identify as disabled. Consequently, when they "feel more like [themselves]" because their disabling fatigue has lifted and they are more in control of their levels of energy than before, they no longer identify as disabled.

(4) A few years ago my fatigue (leftover from my first relapse) was so severe I did consider myself disabled. It took me some time to come to terms with it, but when I stopped being able to really leave my house or effectively do my job because of it, I thought it

\footnotetext{
${ }^{5}$ Aside from some indentation, ellipsis, and underlining for emphasis, all posts are left unedited, as they originally appeared on Reddit.
} 


\section{META-DISCOURSES OF DISABILITY AMONG PEOPLE WITH MS}

probably warranted the label. I really struggled with the idea that being constantly exhausted could be a disability. [...] Thinking of it as a disability (instead of just inexplicable laziness) helped me be kinder towards myself. In the past 6-7 months it's like my fatigue has almost entirely lifted. I still have the occasional day of feeling crappy but I'm [...] feeling more like myself. Now I wouldn't use the label disabled at all. MS is weird. [...] I was very angry with myself for being so tired and thought I'd somehow just become the laziest loser on the planet. I spent a lot of time blaming myself. Thinking of it as a disability took a lot of that blame away, and I think it helps that I also started reading up on disability rights and changed my mindset. [...]

Aside from lack of agency in experiencing their symptoms, another commonality among the users who identified as disabled was the role of the state or government in justifying their use of this label, specifically with regard to receiving salary compensation or being granted a permit to park in spots reserved for people with mobility challenges. For example, the user below identifies as disabled and immediately cites meeting the (American) government's criteria for disability as a supporting factor for doing so, juxtaposing this claim with the fact that they don't outwardly appear disabled:

(5) well, I certainly feel disabled. I pass the litmus test of government approval. i look tired but otherwise fine.

As I've already mentioned, for the purposes of this paper, I was initially looking for which way of referring to being disabled, if any, people with MS preferred, so the first sentence of (5) would have sufficed as an answer to my question. However, the author mentioning that they passed the government's litmus test for disability suggests that perhaps people with MS have been challenged on the claim that they are disabled. One reason for this might be the invisible nature of MS. In fact, not looking disabled and yet identifying as such anyway was a theme shared with other users, for example:

(6) I am young and outwardly/visually "not disabled", but when I get too hot I have trouble walking. I also just get exhausted and overheated easily (as I'm sure you're all familiar with).

This even seemed to cause the person with MS to be challenged by others for identifying as disabled:

(7) I had someone mutter behind me once 'she doesn't look disabled' and I turned around and said 'and you don't look like a dumb bitch, guess looks can be deceiving huh?!'

As these examples show, some may not consider having an illness that is invisible a legitimate reason to identify as disabled. They may believe that there must be some authoritative third party's support for saying one is disabled if it is not immediately obvious. Indeed, some users identified as disabled in the context of justifying to strangers why they parked in a spot reserved for people with disabilities, an accommodation that only governmental institutions can grant. For instance:

(8) OMG some old lady did that to me the other day. I'm 36, she must have been $80+$. She's giving me the side eye as I threw the truck in park, and as I'm opening my door 
she scoots over to my truck at Mach 5 to get to me in time (trust me lady, I can't run from you).So then she lets out this little nugget:> "Hey you can't park here! These spots are for old people who can't walk anymore!". I use my "tech support voice" (super condescending "you're an idiot and I'm smarter than you, shut your mouth and listen to me" voice): > "No, actually - these are for *disabled* people, which I certainly am. $[\ldots]$

(9) I had someone pull the "you're not disabled" one on me once when I hopped out of my car that was parked in disabled spot. I pointed at my placard and responded "I'm pretty sure my Neurologist with his multiple decades of med school and practice knows more about my disability than your drunk a $\$ \$$." (This was outside a bar). He shut the heck right up.

As shown in the above examples, despite its somewhat temporary nature, it appears that some people with MS do identify as disabled or as a person with a disability and that they do so for a variety of reasons. These can be to resist blame (from themselves or others) for not meeting the social expectations for a normal life as a consequence of the symptoms they experience, or to resist being negatively labeled in some other, such as lazy or as someone who uses reserved parking spots when they should not, effectively breaking the law.

In any case, saying that one is disabled can be a way to assert one's identities, set limits for what they can physically or cognitively do, and justify their use of government accommodations such as having salary compensation or disability parking permits.

\subsection{Why some people with MS choose not to identify as disabled}

Having looked at why and how some users on Reddit identified as disabled as a result of having MS, this section will explore the responses of users who did not identify as disabled and gave no other word or phrase relating to disability to describe themselves.

Given the temporary nature of MS and the variety of ways it affects people as discussed in Section 2, it is not surprising that there were some respondents who did not identify as disabled. Most of these people cited the fact that they are not very affected by MS as the main reason, for example:

(10) I'm fortunate to not be really disabled (though during my flare up, I thought that I'd barely walk again), so I celebrate my mobility and the fact that I don't need the handicap spots by deliberately parking as far from my destination as reasonable and enjoying the walk. It's a little protest against the future knowing that one day I might need that spot and wish that I'd walked more.

(11) I'm apparently very lucky to not be profoundly disabled when taking into consideration the extent of damage in my brain, so I'm going to continue to live my life to the fullest.

For these two users in particular, not being disabled by MS is directly related to "living their lives to the fullest" either by making use of their ability to walk, or as a general practice. Unlike the responses of those who did identify as disabled, this kind of discourse places the people with MS in extremely agentive roles, perhaps even more agentive ones than people without the 


\section{META-DISCOURSES OF DISABILITY AMONG PEOPLE WITH MS}

illness would place themselves in. For example, the author of (10) deliberately chooses to park a fair distance from their destination to walk as much as they can. We can assume that somebody without this kind of illness would park closer, not going to this extreme to make use of their ability to walk. Similarly, while the author of (11) writes that they make a mindful effort to live their life to the fullest, it may be that people without MS do not make such a conscious effort to do so. I do not mean to suggest that able-bodied people take their health for granted. Rather, I want to emphasize the agency that people with MS who do not identify as disabled show in their decision not to do so, juxtaposing it with the lack of agency displayed in the texts of people who did consider themselves disabled.

But while the authors of (10) and (11) cited the absence of symptoms in choosing not to identify as disabled, some users who had MS symptoms explicitly resisted the term disabled, as shown below:

(12) I had to explain to my father in law that just because i have hand controls on my car now does not mean that I am in a wheelchair and in constant need of nursing care. I told him I play sports and am tired because I'm freaking busy. I just can't feel the pedals so I needed hand controls. I'm not disabled.

(13) I was working out at my physiotherapists office and bitching to a fellow patient (who had knee surgery) about insurance and when I said something about medications, she said, "Oh yes, it's because of your disability." It really pissed me off being referred to as disabled. I'd never seen myself as disabled and to be labeled as such simply because of my disease made me incredibly angry. This physio's office is more of a hardcore workout which I have been killing but her calling me disabled felt like she was segregating me into a mentality of "you're doing good despite being disabled" rather than "you've worked hard and are killing it." When I initially had my flareup, I had difficulty walking a block but with physio and steroids, that went away pretty quickly. I am, admittedly, in the early stages of the disease but to be called disabled simply because I've been diagnosed feels like people like this woman have already put me in a box that focusses on the worst case scenario of disease progression. If you met me, you'd have no idea anything was wrong with me so to call me disabled simply because I have this disease infuriated me.

In (12) and (13), both users minimize the extent to which MS has affected them. The author of (12) does so with the word just in "I just can't feel the pedals", suggesting that the only thing that is different about their lives with MS is that they need hand controls for driving. In fact, by mentioning that they don't use a wheelchair or need constant home care, they seem to equate being disabled with being debilitated, and use this as a further motivation to resist the term disabled. They eschew this term because, despite having MS, they can still walk, take care of themselves, and play sports, just like somebody without MS can. They also add that the fatigue is not because of MS but because they lead a busy life. In other words, they emphasize the ways in which they are able-bodied and downplay the disabling effects of MS, attributing them instead to something that affects everybody regardless of illness, i.e., being busy. Similarly, the author of (13) minimizes the symptoms of MS by focusing on the ways in which they have overcome them such that they are no longer visibly affected by MS. Like the author of (12), this user does not want to be treated any differently because they have MS. In parallel to "person-first" language, it seems that the 
authors of (12) and (13) prefer an "ability-first" approach to self-identification, though they don't go so far as to subscribe to the affirmative model discussed in Section 1.1. In both of these cases, the writers seem to be or have been restricted in some sense, which, though associated with being disabled, does not necessarily equate to being disabled in the traditional sense (Grue, 2009). This might help explain why they resist the term disabled. By emphasizing restitution and quest, these kinds of narratives "share the salient feature of allowing for a return to normality, and of emphasizing a comparison with a prior or idealized former body" (Grue, 2016, p. 102). The choice to focus on what is still more or less normal in spite of the illness is not surprising. As Grue writes, "very few people start out wanting to think of themselves as disabled, partly because of the persistence of stigma and disadvantage" (2016, p. 101). This would also explain why the author of (13) seems to equate being disabled with the "worst-case scenario", i.e., being in the later stages of disease progression.

Interestingly, disadvantages and stigma associated with disability can also come from the very institution that provides accommodations for them: the government. That was certainly the case for the author of (13) who went on to write the example below:

(14) It's been my lifelong dream to live in New Zealand. I've lived there before pre-dx ${ }^{6}$ and it's where I consider home to be. Except it distinctly says on their immigration website that you'll automatically be turned down for a residency visa if you have a disability on their list. And guess what's on the list. I understand that it's a matter of cost and that they don't want high cost immigrants but I didn't ask for this disease and yet I'm being punished for it. Because they think having the disease automatically makes me disabled. It's infuriating and incredibly condescending that by the country I considered my future home, I'm no longer a person, I'm a disability.

Once again, this author resists equating the diagnosis of MS with being disabled, but in this example, they also reinforce the notion that "many people who 'count' as disabled" in the eyes of institutions do not share this view or identify as disabled themselves" (Grue, 2016, p. 103). As we can see, there is a discrepancy between how this author sees themselves and how the New Zealand government sees them, one that is not without significant consequences for them. This kind of discrepancy was also mentioned by a user who lives in the UK:

(15) When I first got diagnosed last year I had to look into what to tell work and such, as I now live in the UK (originally, I am from Germany). I found out that legally, I am now considered as having a disability - my driver's license has to be renewed every three years instead of five for example, pending an okay from my neurologist. And I am not allowed to donate blood or my organs either. But I don't consider myself disabled at all. I am mostly symptom free still and only the $\mathrm{DMT}^{7}$ medication really reminds me of anything. Quite frankly, that the British government considers me disabled is a weird thought.

The anecdotes above show that though the individuals who wrote them do not identify as disabled in the social and interactional sense of the term, they are nonetheless counted as disabled by the state and are thereby further disabled in a bureaucratic sense (Grue, 2016), i.e., by being

${ }^{6}$ That is, pre-diagnosis.

${ }^{7}$ That is, disease-modifying treatment. 


\section{META-DISCOURSES OF DISABILITY AMONG PEOPLE WITH MS}

subject to different regulations against their will. Building on Grue's statement, it sounds like it is not MS that disables the authors of (14) and (15), but rather the governmental institutions that identify them as such. Besides resisting the term disabled, another common feature across examples (12)-(15) is that users did not like being ascribed this label by others, be it institutions as in (14) and (15), or people as in (12) and (13). However, the next example of a person resisting the term disabled is unique in that it reveals a reluctance to allow oneself to identify as disabled:

(16) This is how I feel about myself (people rarely see things the same as me) but I think that if I am hindered by something like MS - that is bad enough - but for me to put a label on it and wear it like a t-shirt or badge makes me feel worse. Sometimes I do want to park closer to the building because $\mathrm{A}[\mathrm{Z}]$ can be pretty hot.. but at the same time $\underline{\mathrm{I}}$ feel like I am giving up if I acknowledge it. I will fight it with my last breath but never will give it credit until I have no other choice.

As they write in their response, this individual equates identifying as disabled with giving up. That is, they resist the term disabled because they don't want to surrender to MS and abandon the hope of leading a symptom-free life. This anecdote can be compared to example (13) in the sense that the author emphasizes that they want to combat the disease. What is unique about them, though, is that they also see identifying as disabled as wearing their disability like a badge. They are probably paraphrasing the idiom wear like a badge of honour, which refers to taking pride in something that is usually considered negative. If that's the case, wearing their MS as a badge of honour would be strongly reminiscent of the affirmative model of disability, but this author seems to resist doing this, despite the affirmative model's positive interpretations of disability. However, that may be understandable because, according to Grue, "disability [...] cannot be positively valuated essentially in itself because it refers to a form of experience that is, by definition, negative" (2016, p. 101). ${ }^{8}$ Whereas other marginalized people like women and people of colour can celebrate their identities because there is nothing inherently wrong with being a woman or a person of colour, the same cannot currently be said for people with disabilities. As Zola (1982) points out, "despite progress in terms of stigmatization, it's still hard to say things like 'Long live cancer!' or 'Up with MS!', in parallel to other stigmatized groups showing pride in their identities with slogans like 'Black is beautiful!'” (Zola, 1982, as cited in Grue, 2016, p. 97-98). Correspondingly, for the author of (16), having a disability is nothing to be happy about, so they resist this label like they try to resist the effects of the disease.

As examples (10)-(16) have shown, there are many reasons for which someone with MS might chose not to identify as disabled: they may not be profoundly affected by the illness or choose to minimize the ways in which they are affected by it, focusing instead on their abilities and achievements. They may also be perplexed or disappointed by the fact that federal institutions consider them disabled, as it deprives them of certain rights and privileges. Finally, one can resist this term because they believe using it means giving up on living normally and that calling themselves disabled would be the same as celebrating their inherently negative illness.

\footnotetext{
${ }^{8}$ The same claim can be made about the increasing practice of calling people with MS MS Warriors. While empowering for some, because MS is first and foremost an illness, ascribing a label like warrior to someone with little agency in experiencing their symptoms can come off as condescending or even disparaging. See:

https://multiplesclerosis.net/living-with-ms/warrior for more discussion.
} 


\subsection{Terms besides disabled users with MS chose to use}

While the last section looked at why certain Reddit users with MS resisted the term disabled, this section focuses on users who did not identify as disabled and provided another term or phrase with which they associated. There were some alternative ways of referring to the effects of MS that were modifications of the term disability or disabled such as going through periods of disability, having a minimal disability, or being temporarily disabled. These labels focus on the temporary nature of the flare-ups associated with MS as I have discussed above and on their minimal residual effects if the brain lesion has not fully healed. In other words, they portray the effects of MS as not permanently disabling. In fact, one user specifically used this reason to avoid the term disabled, opting instead for un-abled, and adding that they "hope it's a temporary thing". When I asked them to elaborate on what difference they see between these two terms, they wrote:

(17) First, I find the connotation of the word "disability" brings with it a sense if finiteness. Whatever it is, it will never go away. And that, at least right now, is not necessarily the case. [...] I also find it helpful, or better, to use the word "unable" when referencing things that I cannot do with friends or family because it removes the word "disabled" from the conversation. I've been challenged by people who say "well this guy is disabled and he's still able to do ___ or "Look at this person, they taught themselves to overcome their disability to do __. While I understand their thought process of wanting to inspire, it really just feels like they say they don't believe me in what I say my body has limits doing. So by removing the word "disability" or "disabled" and using "unable" instead, it reinforces my limits to those who want to push me or may not quite understand what I mean when I set limits.

Interestingly, aside from wishing to avoid the permanence that the word disabled connotes, this author cites similar experiences to those of people who did identify as disabled, that is, being challenged by others for using this label and having to set boundaries regarding what they can and cannot do, showing that the same experiences can have different effects on the relationship someone with MS has with the term disabled.

Resisting the term disabled to avoid having to argue with or explain their use of the word to others was also cited by the author of the following example, who described themselves as medically retired, by which they meant having a disability pension provided by their government. As was the case for some users whose texts I showed in the previous section, this person's government identifies them as disabled, and yet they do not use the term to refer to themselves:

(18) Medically retired. I'm 34 and qualify for my disability pension, so the term describes me perfectly. [...] I realized recently that rather than being "a person with MS who can no longer work due to compounding disability"... I'm technically "retired" with extra LTD ${ }^{9}$ disability coverage.It's a total shift. Retired young I guess.

When I asked them to elaborate on how others react to this term, they wrote:

(19) Normally they understand and don't give me that pitying or the yeah right look I got with disabled. I think people associate retirement with freedom and ignore the medically. People also seem less likely to tell me I just need more iron or how their

\footnotetext{
${ }^{9}$ That is, long-term disability.
} 


\section{META-DISCOURSES OF DISABILITY AMONG PEOPLE WITH MS}

friend was cured by a crystal when I phrase my current situation without the word disabled.

As we can see, the authors of examples (17)-(19) use an alternative to disabled to avoid engaging with other (potentially uninformed) people in a conversation about their disability. These alternative labels also help them reinforce boundaries on what they can and cannot physically do as well as avoid unpleasant discussions about overcoming the illness (e.g., by having a better mentality or using alternatives to medicine).

In contrast to these writers, though, another user opted for an alternative label to disabled precisely for the purpose of engaging their interlocutors in discussions about being disabled. In response to my question, they wrote:

(20) I go to the extreme and say I am a cripple. There are two basic responses to this. You are not cripple - to which I can respond and explain. Confusion - attempt to ignore what I said. I usually follow up with an explanation to clarify the confusion. In either case I get to educate the audience - which is why I use this approach.

When I asked them for an example of their interlocutors' responses to their explanation of why they consider themselves a cripple, they answered:

(21) Really? Let's go for a 5 minute walk and you will see for yourself ... No one had taken me up on that! I then proceed to explain how the heat affects me, the fatigue, no more sports, seeing double when I look to my right, et.c.

In their posts, like in their lives, the author of (20) and (21) uses what is usually considered to be an outdated, derogatory word to refer to someone with a disability. But as Cameron mentions, this seems to be "intended to make people work at extracting a meaning" (2012, p. 157). Presumably, this user wants their interlocutor to question their assumptions about what being disabled means, one of these assumptions being that a disability is outwardly visible. They draw them into a discussion of these issues with an attention-grabbing word like cripple, which is currently considered politically incorrect and downright offensive. However, there is a move, at least by one user, to change this. Consider the example below:

(22) I routinely use the word cripple as I think it's a word that could do with being reclaimed much as queer was. Cripple is a fact, and although the word has been given an emotive and loaded effect by many sectors in society within the context I work in (disabled art) cripple is seen through the lens of reclamation, as it was in older activist circles.

Not only does this writer advocate for the use of this archaic term in order to reclaim it, but they also argue against using "person-first" language - the more recently prescribed, "polite" alternative to disabled - with a similar argument to the one used by the NFB:

(23) I describe myself as a disabled person because I feel that there is no need to remind people that I am a person even though I am disabled. It's an old argument, but we don't say person with Christianity - because religion is enough of an experience to define a persons identification based on their perceived position in the social group of 
'Christian'. I would argue that my position in the group of 'disabled' - which is put upon me by social structuring and perceptions - is pervasive enough that defining as a disabled person is good and proper.

It is important to add here that, while this user identifies as disabled, it is not due to their MS, which is why I include their response in this section as opposed to 4.1. They explain this in another post:

(24) First off, I'm not coming to MS as a nondisabled person. I was always autistic, and I always had movement and coordination issues. I went though speech therapy etc as a child. I've never been nondisabled, so no doubt this will have affected my view. [...] I don't believe MS is a disability, it is an impairment. And, unlike Cancer -it's not going to kill me. It may cause pain, or fatigue (both of which are true in my case) but these are simply facets of human experience that with the right support/frame of mind do not have to be disabling. These are negative experiences, but disabled or not- we all have negative experiences, and oftentimes they differ from person to person.

This user's view of MS as an impairment rather than a disability is reminiscent of an argument by Bury (1991):

The meaning of an illness can be defined in terms of its 'consequences', which refers to the impact it has on practical aspects of the person's roles and relationships in everyday life; or in terms of its 'significance', which relates to the cultural connotations, the symbols and significations, surrounding different sorts of illness and disability (Bury, 1991, as cited in Williams, 1996, pp. 198-199).

Building on the observations of Bury and the author of examples (22)-(24), we might ask whether MS in itself is a disability or whether it's better to think only of its consequences as being (potentially) disabling. As the examples discussed in the previous section showed, there are individuals with MS who do not feel disabled by it because they don't experience its symptoms, or don't experience them to such a degree that it impacts their daily lives. As well, the symptoms of MS, namely lack of coordination, weakness, vision problems, bladder problems, and cognitive impairment (MS Society of Canada, 2018), are not uncommon among non-disabled people in our society, such as the elderly. This was another reason this author cited for avoiding the term disabled: while the symptoms of MS are negative, they tend to affect everybody, even people without MS, sooner or later. This view was shared by a different user who opted for the terms limited, pre-aged, or slowed:

(25) I think of myself as a person! Okay, so maybe a person with some early limitations. In the early days I used to think of myself as disabled. [...] I eventually shed the disabled label and went with "limited." Really though, I now just think of myself as having different operating parameters as most people "my age" but recognize that all people operate on a spectrum. Honestly, one day I finally realized that all people eventually accumulate some form a disability, usually in their 60's-80's. As people age they experience brain degeneration and atrophy, slowed healing and regeneration, and numerous other things. I don't generally see these people as having disabilities, I just see them as people just being/getting old(er). So, based on that I have a strange view of MS. I only use the term disability or limit when speaking to others. I feel I am more 


\section{META-DISCOURSES OF DISABILITY AMONG PEOPLE WITH MS}

or less presented with the challenges of premature aging at age (36). [...] If I had to use a term I'd go with limited, pre-aged or slowed but not disabled. Im just a person with different operating parameters.

As this user explains, rather than viewing themselves as disabled by MS, they simply see themselves as aging earlier because of it. Thus, even though the term disabled is inherently negative, thanks to this viewpoint, this author manages to find some positivity in their early aging that perhaps the word disabled does not carry. They add:

(26) I also realized that I'm kind of pre-aging at a time when I technically have more physical and cognitive reserve and also bandwidth for learning new things like compensation strategies, adaptation skills, and coping mechanisms. I'm also doing it at an age where I'm more apt to be be able to reframe and shape my thinking patterns and habits now hopefully be adaptable and positive in the future. Basically I'm making it my mission and habit now to problem solve and figure out alternative ways to do stuff.

Like other writers from Section 4.2 who resisted the term disabled, this individual is emphasizing what they can do-learn new things, adapt, and cope-which makes them feel better about their illness, thus showing a kind of agency in having MS that, as discussed, is in contrast with both the medical model of disability and the texts of those in Section 4.1 who did identify as disabled. Furthermore, it seems that this author feels empowered by the terms limited, pre-aged, or slowed. This may be unexpected, given that it is usually offensive to call someone else by those labels, but it does support the argument that people with MS — indeed, with any disability — should have a say in which terms are used to refer to them.

Indeed, this section has shown that disabled, person with a disability, disabled person and other such labels do not completely account for the experiences of all people with MS. People who resist the term disabled offer other ways to talk about the effects of their illness. For instance, those who want to avoid the permanent connotation of the word disabled might emphasize the temporality of MS symptoms by saying that it puts them through periods of disability, temporarily disables them, or that they have a minimal disability. Others who have suffered more greatly as a result and are now on disability pension might use labels like medically retired. Some even go so far as to say they are cripples, either to start a conversation about disability with their interlocutors or in an attempt to reclaim the word and give it a positive connotation. Finally, users also compared their MS symptoms to those of aging that are common across the board, and identified as pre-aged or limited, which may support an analysis of MS as potentially disabling, though not in itself a disability.

\section{Conclusion}

What I have aimed to show in this paper is that people with MS, at least on Reddit, relate to the word disabled in many different ways. Though these ways can be grouped into three major categories-identifying as disabled, resisting the term, or using a different term to describe themselves - each user had a unique relationship to the word that was reflective not only of the effects of MS on their individual physical and cognitive abilities but also of their relationships with other people and the rights granted or denied to them by institutions like the government as a result of experiencing MS symptoms. Generally, those who did identify as disabled represented themselves as having little to no agency in experiencing their symptoms, but they also wanted to resist blame for not functioning "normally" in some respect. Thus, they placed emphasis on MS 
for impairing them, which variedly resulted in the government granting them some form of accommodation like a disability parking pass.

On the other hand, those who resisted the term disabled tended to place themselves in highly agentive roles, focusing not only on what they can still do in spite of their illness, but also doing so to an extreme in order to beat or fight it. Some even challenged the views of other people or certain governments in terms of identifying them as disabled when it resulted in the unfair loss of a right or choice such as donating organs or immigrating to a new country. Among these respondents were people who used a term other than disabled to describe the impact MS has had on their lives. Some focused on the temporary nature of the illness, using phrases like minimal disability or temporally disabled, while others either avoided or prompted a discussion about disability using terms like medically retired or crippled, respectively.

These highly varied results may be an indication that aiming for and attempting to prescribe a neutral way to describe individuals with disabilities is ineffective, and that it may be better to accept the many ways in which individuals with MS and other disabilities refer to themselves, including how they negotiate this label with their interlocutors. This study has shown that, in terms of the discourse of disability, people with MS are not only aware of the many labels that can be used to refer to the results of their illness, but they also, for the most part, ignore prescribed politically correct terms as well as the models of disability, opting for words like disabled and even archaic, offensive terms like cripple. Therefore, despite perhaps not having agency in experiencing their symptoms or being diagnosed, people with MS show a high degree of agency in terms of how they refer to themselves. As such, they seem to be reclaiming the discourse of disability (cf. Corker and French, 1999), and perhaps rightfully so, since who could understand the effects of disabilityespecially in a social sense-better than those who experience it?

\section{Acknowledgements}

I would like to thank my friend, Patrick Pugh, for writing the script that I used to gather my data. I would also like to thank Professor Philipp Angermeyer and WALLY co-editor Brittney O’Neill for their helpful suggestions for revisions on this paper. All remaining errors are my own.

\section{References}

Barnes, C. \& Mercer, G. (1997). Breaking the mould? An introduction to doing disability research.

In Barnes, C., \& Mercer, G. (Eds.). Doing disability research (pp. 1-14). Disability Press.

Bolt, D. (2003). Blindness and the problems of terminology. Journal of Visual Impairment and Blindness, 97(9), 519-520. https://doi.org/10.1177/0145482X0309700903

Cameron, D. (2012). Verbal hygiene. Routledge.

Corker, M., \& French, S. (1999). Disability discourse. Open University Press.

Ehrlich, S., \& King, R. (1994). Feminist meanings and the (de)politicization of the lexicon. Language in Society, 23(1), 59-76.

Grue, J. (2009). Critical discourse analysis, topoi and mystification: Disability policy documents from a Norwegian NGO. Discourse Studies, 11(3), 305-328.

https://doi.org/10.1177/1461445609102446

Grue, J. (2016). Disability and discourse analysis. Routledge.

Multiple Sclerosis Society of Canada. (2018). Multiple sclerosis society of Canada. Retrieved June 14, 2018, from https://mssociety.ca/about-ms/what-is-ms

Oliver, M. (1996). Defining impairment and disability: Issues at stake. In Barnes, C., \& Mercer, G. (Eds.). Exploring the divide: Illness and disability (pp. 29-54). Disability Press.

Shakespeare, T. (2000). Helpless. In Help (pp. 1-20). British Association of Social Workers. 


\section{META-DISCOURSES OF DISABILITY AMONG PEOPLE WITH MS}

Shakespeare, T. (2018) Disability: The basics. Routledge.

Stamou, A. G., Alevriadou, A., \& Soufla, F. (2016). Representations of disability from the perspective of people with disabilities and their families: A critical discourse analysis of disability groups on Facebook. Scandinavian Journal of Disability Research, 18(1), 1-16. https://doi.org/10.1080/15017419.2014.962611

Williams, G. (1996). Representing disability: Some questions of phenomenology and politics. In Barnes, C., \& Mercer, G. (Eds.). Exploring the divide: Illness and disability (pp. 194-212). Disability Press.

\section{Appendix A: My Reddit post}

Hi, everyone.

First of all, I want to say that I'm collecting this data for a research paper* on the word "disabled" and how people with MS see themselves/prefer to be referred to in terms of this word.

I myself was diagnosed with MS in March 2018, and I have trouble deciding whether or not I'm disabled, especially given the temporality of flare-ups associated with MS (which prompted me to write this paper). For example, my first (and only) flare-up was double vision in my left eye. While that could be considered a visual impairment, the symptom is long gone and so I wonder about my status as a person with a disability.

So what do you all think? Do you consider yourself a disabled person, a person with a disability (or who lives with/has a disability), a person disabled by society, or something else? Any and all responses are appreciated, and I thank you SO much.

*More information about me and my paper:

I'm a PhD candidate in linguistics. My paper is on how people with MS view themselves in terms of the word "disabled" (or words like it such as disability, person with a disability, or other expressions). This subject is close to my heart because I was recently diagnosed. I'm hoping to publish and present this paper to raise awareness about MS and to open a discussion about terms related to having disabilities. All responses that make it into the paper will be anonymized. I'd be happy to answer any additional questions you might have. 